\title{
Correction to: The Personal Can Be Political: Deconstructing Representations of Anglo-Indians
}

\author{
Dolores Chew
}

\section{Correction to:}

Chapter 11 in: R. Andrews, M. S. Raj (eds.), Anglo-Indian Identity, https://doi.org/10.1007/978-3-030-64458-1_11

The affiliation of the author was inadvertently published wrong and it has been corrected now as "Marianopolis College, Montreal, QC, Canada."

The updated version of the chapter can be found at https://doi.org/10.1007/978-3-030-64458-1_11

(C) The Author(s), under exclusive license to Springer Nature Switzerland AG 2021

R. Andrews, M. S. Raj (eds.), Anglo-Indian Identity, https://doi.org/10.1007/978-3-030-64458-1_19 